\title{
Analisa Penerapan Hierarchical Tokken Buket Untuk Optimalisasi Management Bandwith Pada Server Ubuntu
}

\author{
Riska Haerani ${ }^{1}$, Lalu Zazuli Azhar ${ }^{2}$
}

${ }^{1,2}$ Fakultas Teknik, Universitas Bumigora, Mataram

riska.haerani@gmail.com ${ }^{1}$, pujutsega@gmail.com ${ }^{2}$

\begin{abstract}
Abstrak
Perkembangan teknologi informasi pada saat ini semakin cepat, berdasarkan pada kebanyakan area hotspot belum memiliki system pada server untuk melakukan optimalisasi management bandwith. Sehingga karena terbatasnya bandwith pada area-area hotspot tersebut menyebabkan koneksi disetiap user terganggu karena belum mempunyai system untuk melakukan management bandwith dan pada sisi operator melakukan pembatasan jumlah bandwith yang diberikan. Metodologi penelitian yang digunakan adalah Network Development Life Cycle (NDLC), terdapat tiga tahapan yang digunakan yaitu analysis, design, simulation prototyping. Pada tahap analysis memuat tentang pengumpulan data, tahap design memuat tentang rancangan jaringan sedangkan tahap simulation prototyping memuat tentang instalasi konfigurasi dan ujicoba. Terdapat 3 ujicoba yang dilakukan yani dengan melakukan pengetesan bandwith menggunakan speedtest, melakukan unduh file menggunakan IDM, dan melakukan streaming youtube, untuk skenarionya dengan melakukan ujicoba setelah penerapan dan sebelum HTB diterapkan. Dari permasalahan yang dipaparkan diatas, penulis ingin membuat system untuk pengoptimalisasi penggunaan bandwith dengan metode HTB (Hierarchical Token Bucket), sehingga dapat mengoptimalkan penggunaan bandwith dan melakukan penyetaraan terhadap pemakaian dari user. Pada pengujian speedtest sebelum di aktifkan HTB untuk unduh di dapatkan kecepatan 11,32 Mbps sedangkan untuk unggah 10,93 Mbps, untuk streaming Youtube 6,992 Mbps. Setelah diaktifkan HTB maka pengujian speedtest untuk unduh 1,1 Mbps sedangkan untuk unggah 1,63 Mbps, untuk streaming Youtube 1,025 Mbps.
\end{abstract}

Kata Kunci : HTB, Jaringan, Server, Speedtest, IDM, Youtube

\begin{abstract}
The development of information technology is increasingly rapid, based on most hotspot areas do not yet have a system on the server to optimize bandwidth management. So because the limited bandwidth in these hotspot areas causes the connection in each user to be interrupted because it does not yet have a system to do bandwidth management and on the operator side does limit the amount of bandwidth given. The research methodology used is Network Development Life Cycle (NDLC), there are 3 stages used namely analysis, design, simulation prototyping. In the analysis phase contains about data collection, the design stage contains about network design while the simulation prototyping stage contains about configuration installation and trials. There are three trials conducted by testing bandwidth using speedtest, downloading files using IDM, and streaming youtube, for the scenario by doing a test after implementation and before HTB is applied. From the above problems, the author wants to create a system for optimizing the use of bandwidth with the HTB (Hierarchical Token Bucket) method, so as to optimize bandwidth usage and equalize the usage of the user. In the speedtest test before activating HTB for download, it gets a speed of 11.32 Mbps while for uploading 10.93 Mbps, for streaming Youtube 6.992 Mbps. After activating HTB, the speedtest test is to download 1.1 Mbps while for uploading $1.63 \mathrm{Mbps}$, for streaming Youtube 1.025 Mbps
\end{abstract}

Keywords : HTB, Network, Server, Speedtest, IDM, Youtube

\section{PENDAHULUAN}

Manajemen bandwidth merupakan salah satu cara untuk mengelola koneksi internet bagi perusahaan, institusi maupun sekolah agar koneksi internet yang terbatas bisa dinikmati oleh banyak orang walaupun bandwith yang disewa tidak terlalu besar. Institusi yang menggunakan jaringan computer dan internet sebagai pendukung pekerjaan akan memerlukan pengelolaan bandwidth, terutama jika jaringan tersebut mempunyai beberapa divisi, dimana tiap divisi belum tentu memerlukan koneksi internet dengan koneksi cepat. Maka dengan pengelolaan bandwidth akan memberikan keuntungan bagi institusi[1]

Esdinar Manalu, dkk (2017), dalam penelitian ini menerapkan kontrol penggunaan internet, 
menerapkan manajemen bandwidth dan menstabilkan koneksi internet. Metode antrian yang digunakan dalam penelitian ini yaitu menggunakan metode Hierarchical Token Bucket (HTB). Tujuan utama dari metode ini yaitu membuat manajemen bandwidth menggunakan router mikrotik pada jaringan wi-fi dengan metode simple queue untuk mengatasi masalah jaringan internet sehingga dapat membagi bandwidth secara merata kepada setiap user.)[2].

Dian Kurnia (2017), dalam penelitian ini dilakukan menggabungkan beberapa teknik antrian dan parameter QoS (quality of service) dan dilakukan analisis performansi sistem manajemen bandwidth menggunakan metode HTB (Hierarchical Tocken Bucket), PCQ dengan layer 7 protocol sebagai limit file berekstensi, PCQ rate limit dan Hotspot [3].

Lukman, dkk (2018) membahas tentang cara penerapan Hierarchical Token Bucket yang diterapkan diperangkat mikrotik untuk melakukan management bandwith terhadap jaringan hotspot RT/RW net pada sebuah layanan hotspot public yang dimana sebelum penerapan HTB banyak keluhan tentang bandwith yang didapat tidak sesuai dengan paket yang dipilih dan menimbulkan ketidaknyamanan pengguna[4].

Terbatasnya bandwith pada suatu area hotspot menyebabkan koneksi disetiap user terganggu karena belum mempunyai system untuk melakukan management bandwith dan pada sisi operator melakukan pembatasan jumlah bandwith yang diberikan. Pada saat ini semakin tingginya tingkat kebutuhan akan internet, tentunya hal ini menjadi masalah tersendiri bagi area-area hotspot apabila tidak memiliki system yang memadai. Tanpa adanya management bandwith, banyak client yang dapat menggunakan internet secara tidak beraturan, sehingga menyebabkan client yang lain tidak mendapatkan jatah bandwith yang sesuai. Untuk memanagement bandwith rupanya belum mampu dilakukan oleh pihak area-area hotspot.

Dari permasalahan yang dipaparkan diatas, penulis ingin membuat system untuk pengoptimalisasi penggunaan bandwith dengan metode HTB (Hierarchical Token Bucket) mengunakan server Ubuntu, HTB merupakan salah satu metode antrian yang adil dan bertujuan menerapkan fungsi link sharing untuk setiap client. Pada HTB terdapat TBF (Token Bucket Filter) yang berfungsi sebagai alat estimator yang sangat mudah diimplementasikan dikarenakan hanya dengan menggunakan parameter rate HTB dapat mengeset rate bandwidth yang akan diberikan kepada client. Kelebihan HTB yang lainnya yaitu memiliki parameter ceil yang akan mengatur bandwidth pengguna di antara base rate dan nilai ceil rate-nya. Parameter ceil ini juga merupakan alternatif HTB dalam membagi bandwidth ke client dikarenakan HTB akan memberikan bandwidth yang tersisa apabila bandwidth keseluruhan tidak digunakan oleh client dengan syarat bandwidth tersisa yang akan diberikan masih dibawah nilai rate ceil yang diset. HTB merupakan salah satu metode yang mampu memaksimalkan pengoptimalisasian management bandwith, sehingga kualitas pelayanan menjadi lebih meningkat dan terjadi pemerataan bandwidth sesuai prioritasnya saat kondisi traffic seluruh paket penuh. Sehingga dapat mengoptimalkan penggunaan bandwith dan melakukan penyetaraan terhadap pemakaian dari user.

\section{METODOLOGI}

\subsection{Hierarchical Token Bucket}

HTB merupakan teknik yang menggunakan Classful Queueing Disciplines yang memperbolehkan paket diarahkan ke class tertentu dan antrian subqueues. Sebaik apa HTB dalam melakukan pengelolaan bandwidth masih perlu diketahui lebih lanjut[5].

\subsection{Cara Kerja HTB}

Cara Kerja $H T B$ tidak ada perbedaan dengan pendahulunya yaitu $C B Q$, hanya saja pada General Scheduler HTB menggunakan mekanisme Deficit Round Robin (DRR) dan pada blok umpan baliknya, Estimator HTB tidak menggunakan Eksponential Weighted Moving Average (EWMA) melainkan Token Bucket Filter (TBF)[6]

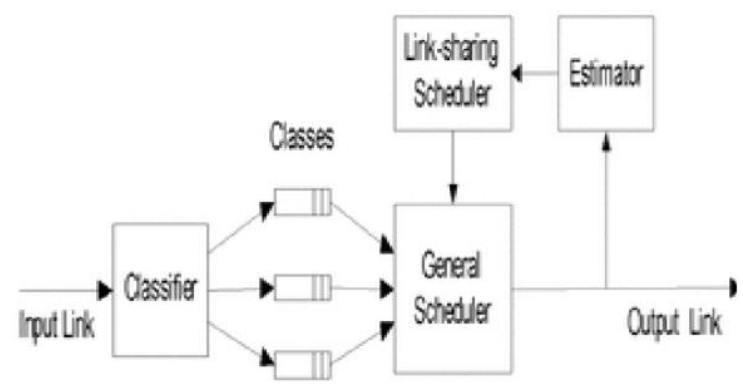

Gambar 1 Deficit Round Robin[7]

\subsection{Linux}

Linux adalah software system operasi open source yang gratis untuk disebarluaskan di bawah lisensi $G N U$. Jadi pengguna diijinkan untuk menginstal pada computer ataupun menyalin dan menyebarluaskan tanpa harus membayar. Salah satu media dalam pembelajaran Linux adalah kamus yang dapat digunakan untuk mencari arti dari kata-kata ataupun 
kode yang tidak diketahui. Pemanfaatan mobile phone dalam bidang pendidikan dikenal dengan istilah mobile learning. Mobile learning merupakan sebuah paradigm baru yang telah menciptakan lingkungan pembelajaran baru yaitu pembelajaran yang didukung oleh mobile phone dan transmisinir kabel berupa teknologi selular.[8]

\subsection{Bandwith}

Bandwidth, merupakan rate transfer data maksimal yang dapat diteruskan antara dua titik. [9]

\subsection{Manajemen Bandwith}

Manajemen bandwidth merupakan salah satu cara untuk mengelola koneksi internet bagi perusahaan, institusi maupun sekolah agar koneksi internet yang terbatas bisa dinikmati oleh banyak orang walaupun bandwith yang disewa tidak terlalu besar. Institusi yang menggunakan jaringan komputer dan internet sebagai pendukung pekerjaan akan memerlukan pengelolaan bandwidth, terutama jika jaringan tersebut mempunyai beberapa divisi, dimana tiap divisi belum tentu memerlukan koneksi internet dengan koneksi cepat. Maka dengan pengelolaan bandwidth akan memberikan keuntungan bagi institusi.[10]

\subsection{VMware}

VMware adalah teknologi buatan Dell yang menyediakan platform perangkat lunak (software) untuk melakukan virtualisasi. Tidak hanya software untuk membuat mesin virtual saja, tetapi mereka juga memberikan layanan pendukungnya. Nama VMware sendiri diambil dari cabang milik Dell yaitu VMware, In. Dengan software VMWare Kita bias menginstalkan beberapa system operasi termasuk Linux, Windows, pada waktu yang sama tanpa kita merestart ulang $P C$. Secara mudahnya dapat dikatakan sebagai $P C$ di dalam sebuah $P C$.[11]

\subsection{Server}

Server merupakan sistem komputer yang menyediakan layananlayanan tertentu seperti sistem operasi, program aplikasi maupun data-data informasi kepada komputer lain yang saling terhubung dalam sebuah jaringan komputer. Mengingat fungsi yang dimiliki server adalah memberikan layanan kepada client, maka server dituntut untuk bisa melayani permintaan (request) dari semua client.[12]

\subsection{Client Server}

Client server merupakan jaringan yang didesain untuk pengguna, yaitu pengguna tersebut disebut dengan client, untuk mengakses sumber daya seperti lagu, koleksi video, atau beberapa layanan lainnya dari komputer pusat yang disebut server. Jaringan client server merupakan dimana satu komputer terpusat (server) adalah pusat dimana banyak komputer pribadi atau workstation yang sangat kuat (disebut client) terhubung. Client menjalankan aplikasi dan mengakses data yang tersimpan dalam server.[13]

\subsection{IPTables}

Iptables merupakan firewall yang cukup dominan digunakan karena memiliki berbagai macam kemampuan untuk melakukan pengaturan terhadap keluar masuknya paket data[12]

\subsection{TCP/IP}

TCP/IP protocol suite terdiri dari banyak protocol dengan dua protocol utama, yaitu Transport Control Protocol (TCP), dan Internet Protocol (IP). Dalam protocol jaringan TCP/IP, sebuah port adalah mekanisme yang mengizinkan sebuah computer untuk mendukung beberapa sesi koneksi dengan computer lainnya dan program didalam jaringan. Port dapat mengidentifikasi aplikasi dan layanan yang menggunakan koneksi didalam jaringan TCP/IP. Sehingga port juga mengidentifikasi sebuah proses tertentu dimana sebuah server dapat memberikan layanan kepada client atau bagaimana sebuah client dapat mengakses layanan yang ada pada server[13]

\subsection{Network Development Life Cyle}

Metodelogi penelitian yang digunakan adalah Network Development Life Cycle (NDLC), NDLC merupakan suatu model yang melakukan perancangan dan mendefinisikan pengembangan siklus dari jaringan komputer. $N D L C$ juga merupakan metode yang bergantung dari pembangunan jaringan komputer sebelumnya. NDLC terdiri dari 6 tahapan yaitu analysis, design, simulation prototyping, implementation, monitoring dan management. Keenam tahapan yang terdapat pada $N D L C$, seperti pada gambar 2.

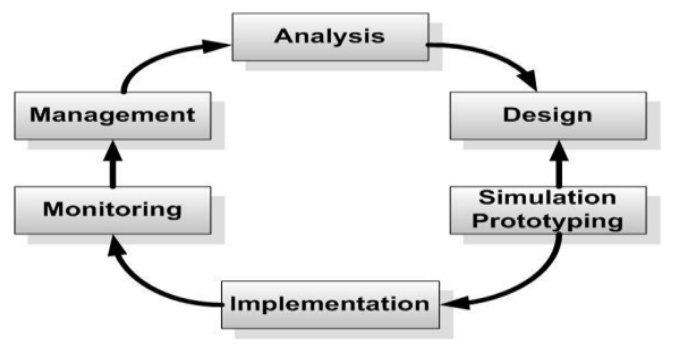

Gambar 2 Flowchart NDLC

Dari 6 tahapan yang ada, penulis hanya menggunakan 3 tahapan yaitu analysis, design dan simulation prototyping. Sehingga dari 3 tahapan 
tersebut penulis dapat melakukan penerapan terhadap Hierarcichal Token Bucket dan melakukan analisa pada saat sebelum diterapkannya Hierarcichal Token Bucket maupun setelah diterapkan, Berikut penjelasan dari 3 tahapan yang digunakan yaitu:

\subsubsection{Tahap Analisis}

Pada tahapan ini penulis melakukan pengumpulan data baik dari berbagai artikel maupun jurnal ilmiah yang melakukan pembahasan terkait dengan management bandwith menggunakan metode Hierarcichal Token Bucket yang dipadukan dengan 3 client sebagai bahan dalam melakukan ujicoba.

\subsubsection{Tahap Design}

Pada tahapan ini terdiri dari tiga tahapan yaitu rancangan jaringan ujicoba, rancangan pengalamatan ip dan kebutuhan perangkat keras dan perangkat lunak.

\section{1) Rancangan jaringan ujicoba}

Rancangan jaringan ujicoba yang digunakan dalam penelitian ini terlihat seprti gambar berikut:

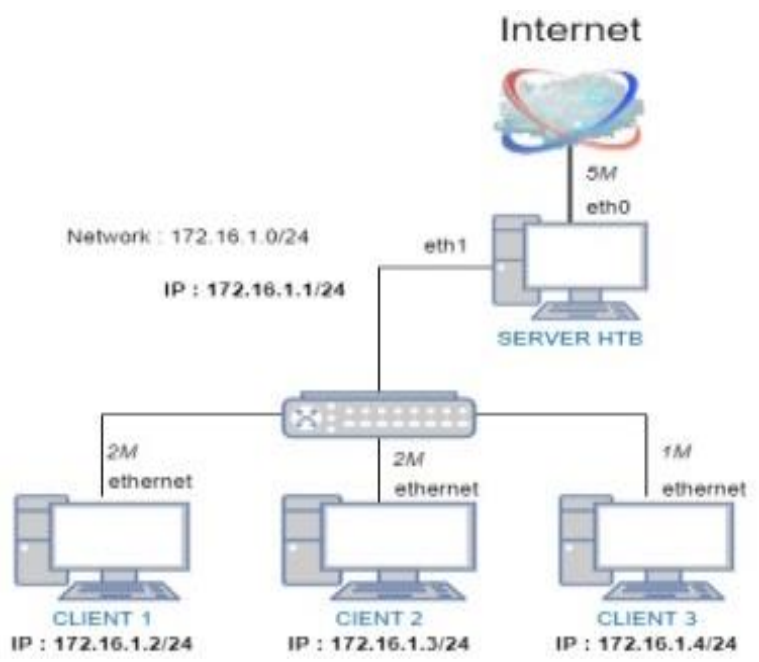

Gambar 3 Rancangan Topologi

Adapun penjelasan dari topologi uji coba $H T B$ diatas adalah sebagai berikut:

a) Pada sisi server sudah dilakukan konfigurasi untuk setiap client yang akan melakukan koneksi terhadap jaringan dengan menggunakan metode Hierarchical Tocken Bucket sebagai bahan untuk melakukan pengaturan terhadap Bandwith yang akan diatur dan yang akan diberikan pada setiap client.

b) Setiap ada request koneksi yang masuk ke server dari pihak client akan di cek oleh server menggunakan file konfigurasi dari tools HTB, apabila client tersebut tidak sesuai dengan aturan pada file konfigurasi $H T B$, maka client tersebut tidak dapat dilakukan Management Bandwith karena belum terdaftar pada file konfigurasi.

c) Server Ubuntu sebagai jalur penghubung akses internet terhadap jaringan yang ada pada jaringan tersebut yang dimana Sistem Operasi dari client menggunakan Sistem Operasi Windows 7.

d) Pada client tidak bisa melakukan koneksi jaringan apabila pada sisi server mati, karena server disini difungsikan sebagai gerbang atau jalur terhubungnya client ke internet.

e) Server akan melakukan pengecekan konfigurasi dari file Hierarchical Tocken Bucket yang ada pada server dan selanjutnya yang akan diproses untuk client-client yang akan melakukan koneksi.

f) Setiap client yang akan melakukan koneksi jaringan, client-client tersebut akan melewati server sebelum terhubung ke jaringan internet.

\section{2) Rancangan pengalamatan IP}

Desain pengalamatan IP pada ujicoba analisa penerapan Hierarchical Tocken Bucket untuk optimalisasi Management Bandwith pada Server Ubuntu ini menggunakan kelas B dengan 1 alamat network 172.16.1.0/24. Untuk keterangan pengalamatan yang digunakan pada jaringan ujicoba ini dapat dilihat pada tabel 1 berikut:

Tabel 1 Tentang Rancangan Pengalamatan IP

\begin{tabular}{|c|c|c|c|c|}
\hline No & Perangkat & IP Address & Netmask & Ket \\
\hline 1 & Server & DHCP & DHCP & eth0 \\
\hline 2 & Server & 172.16 .1 .1 & 255.255 .255 .0 & eth1 \\
\hline 3 & Client 1 & 172.16 .1 .2 & 255.255 .255 .0 & ethernet \\
\hline 4 & Client 2 & 172.16 .1 .3 & 255.255 .255 .0 & ethernet \\
\hline 5 & Client 3 & 172.16 .1 .4 & 255.255 .255 .0 & ethernet \\
\hline
\end{tabular}

\section{3) Rancangan Alur Kerja Sistem}

Gambar 4 dibawah ini adalah rancangan flowchart proses dari alur kerja system yang akan dibuat, seperti terlihat dari gambar berikut: 
e-ISSN. 2685-4066

DOI 10.30812/bite.v2i2.917
Jurnal Bumigora Information Technology (BITe)

Vol.2 No.2 (September) 2020, Hal 139-148

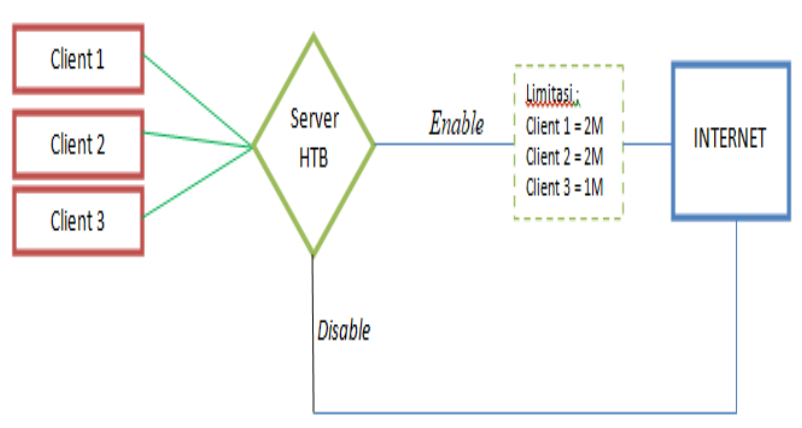

Gambar 4 Rancangan alur kerja system

Adapun penjelasan dari alur kerja sistem $H T B$ diatas adalah sebagai berikut:

a) Client 1, 2 dan 3, terhubung ke server $H T B$, yang dimana server $H T B$ terhubung langsung ke Internet.

b) Pada server $H T B$, konfigurasi limitasi Bandwidth untuk masing-masing client sudah diatur, yaitu client 1 mendapat bandwidth 2M, client 2 mendapatkan bandwidth 2M, dan client 3 mendapatkan Bandwidth 1M.

c) Jika service HTB diaktifkan pada server, maka pembagian limitasi Bandwidth akan dijalankan dan diberikan limitasi sesuai konfigurasi yang sudah diatur.

d) Jika service HTB pada server tidak dijalankan (disable), maka semua client tidak akan diberikan limitasi bandwidth (client akan menggunakan seluruh Bandwidth yang ada pada server).

4) Identifikasi Kebutuhan Perangkat Keras dan Perangkat Lunak

Dalam melakukan analisa system yang akan dibangun, terdapat beberapa kebutuhan perangkat yakni dari perangkat keras maupun perangkat lunak yang digunakan untuk melakukan implementasi dan tahapan ujicoba system. Adapun kebutuhan yang merupakan dari perangkat keras dan perangkat lunak sistem adalah sebagai berikut:

\section{a) Kebutuhan Perangkat Keras}

Terdapat beberapa buah kategori kebutuhan perangkat keras pada system yang dibangun. Adapun kebutuhan perangkat keras yang digunakan sebagai berikut:

Kebutuhan Perangkat Keras Server yang digunakan ialah:

- Laptop Processor AMD A4-9120

- Random Access Memory 1 GB

- Hard Disk 20 GB

- Keyboard
- Mouse

- Network Adapter

Kebutuhan Perangkat Keras client 1 yang digunakan ialah:

- Laptop Processor AMD A4-9120

- Random Access Memory 1 GB

- Hard Disk 60 GB

- Keyboard

- Mouse

- Network Adapter

Kebutuhan Perangkat Keras client 2 yang digunakan ialah:

- Laptop Processor AMD A4-9120

- Random Access Memory 1 GB

- Hard Disk 60 GB

- Keyboard

- Mouse

- Network Adapter

Kebutuhan Perangkat Keras client 3 yang digunakan ialah:

- Laptop Processor AMD A4-9120

- Random Access Memory 1 GB

- Hard Disk 60 GB

- Keyboard

- Mouse

- Network Adapter

b) Kebutuhan Perangkat Lunak

Terdapat beberapa buah kategori kebutuhan perangkat lunak pada system yang dibangun. Adapun kebutuhan perangkat lunak yang digunakan sebagai berikut:

- VMWare Workstation Pro 14.1.1 yang digunakan untuk melakukan pemvirtualisasian server dan client.

- Sistem Operasi Windows 7 yang digunakan sebagai sistem operasi dasar pada sisi client.

- Sistem Operasi Windows 10 Home yang digunakan untuk melakukan tahapan uji coba.

- Tools aplikasi HTB-tools-0.3.0a-i486-1.tgz yang digunakan untuk optimalisasi Management Bandwith.

- Menggunakan iptables sebagai pengaturan didalam merutekan koneksi internet dari client yang menuju ke server dan selanjutnya yang akan diteruskan ke internet.

- Menggunakan Speedtest untuk melakukan percobaan pengetesan koneksi internet.

- Aplikasi Internet Download Manager yang digunakan untuk melakukan pengecekan Bandwith yang diberikan dalam proses download. 
- Menggunakan Sosial Media Youtube untuk melakukan pengecekan kecepatan download pada saat melakukan pengaksesan video.

\subsubsection{Tahap Simulation Prototyping}

Pada tahapan ini memuat tentang tahap analisa dari data-data yang didapat, instalasi konfigurasi yang dilakukan pada masing-masing perangkat yang digunakan berdasarkan rancangan ujicoba yang akan diterapkan.

\section{1) Konfigurasi Server}

Tahapan pertama adalah melakukan instalasi server Ubuntu 16.04 dan selanjutnya melakukan konfigurasi.Adapun proses yang dilakukan untuk melakukan konfigurasi pengalamatan IP Address pada Server yaitu dengan mengubah interfaces eth 0 dan ethl, dengan melakukan perintah sebagai berikut:

rooteubuntu: \#

nano

/etc/network/interfaces

\section{2) Konfigurasi IP Tables}

Iptables digunakan untuk membuat dan menganalisa tabel-tabel aturan pemfilteran paket ip pada sistem operasi linux dan juga bisa diartikan sebagai salah satu tools yang berfungsi sebagai alat untuk melakukan filter (penyaringan) terhadap (traffic) lalu lintas data.

Perintah untuk melakukan konfigurasi iptables seperti berikut:

root@ubuntu: \# iptables -A FORWARD -i eth0 -n state --state RELATED,ESTABLED -j ACCEPT

root@ubuntu: \# iptables -t nat -A POSTROUTING o eth0 -j MASQUERADE

root@ubuntu: \# iptables -A FORWARD -i eth0 -o -j ACCEPT

\section{3) Konfigurasi Client}

Konfigurasi pengalamatan IP Address pada client yang menggunakan sistem operasi windows 7,yang terhubung dengan server HTB.Konfigurasi ip dilakukan agar client dapat terhubung dengan server dan dapat pula mengakses koneksi internet.

Adapun proses yang dilakukan untuk melakukan konfigurasi pengalamatan IP Address Ethernet pada client 1 yaitu dengan melakukan konfigurasi ip pada $I P v 4$. Seperti terlihat pada gambar 5 berikut:

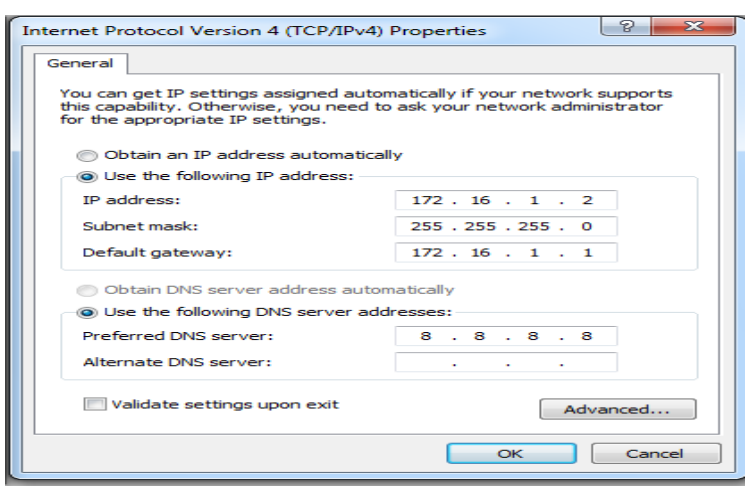

Gambar 5 Hasil Pengalamatan IPv4 Client 1

Pada proses selanjutnya dilakukan konfigurasi pengalamatan IP Address Ethernet pada client 2 yaitu dengan melakukan konfigurasi ip pada IPv4. Seperti terlihat pada gambar 6 berikut:

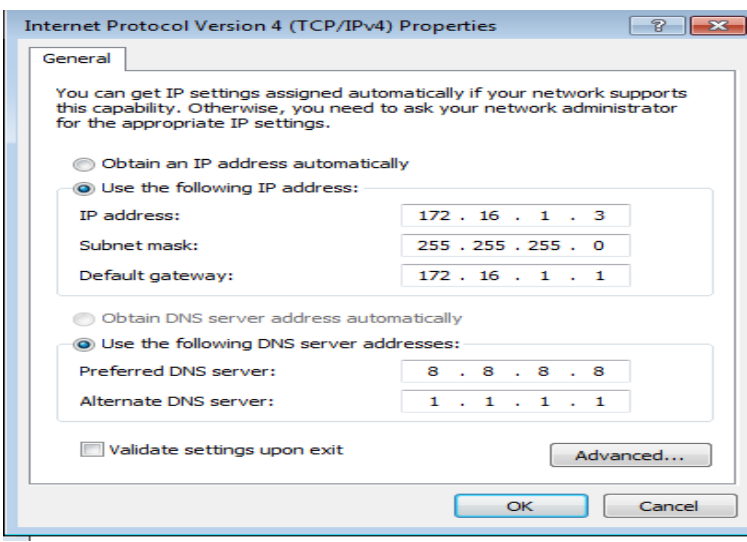

Gambar 6 Hasil Pengalamatan IPv4 Client 2

Kemudian setelah proses diatas selanjutnya dilakukan konfigurasi pengalamatan IP Address Ethernet pada client 3 yaitu dengan melakukan konfigurasi ip pada $I P v 4$. Seperti terlihat pada gambar 7 berikut:

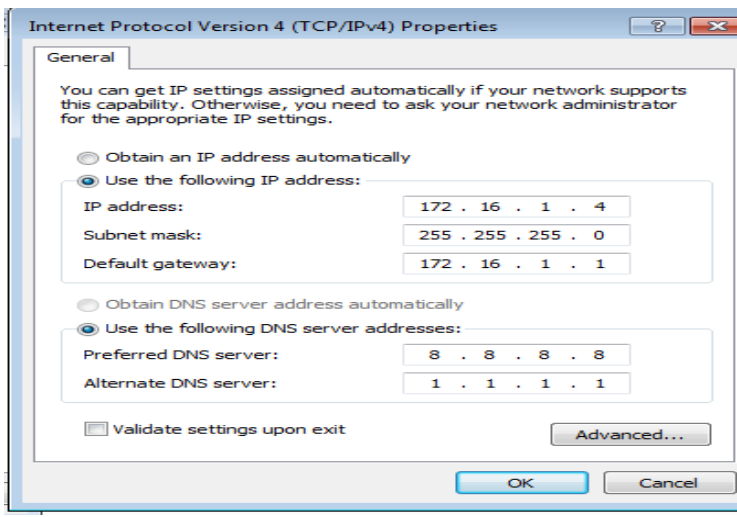

Gambar 7 Hasil Pengalamatan IPv4 Client 3

4) Konfigurasi HTB

Konfigurasi $H T B$ meliputi melakukan instalasi paket tools HTB agar nantinya tools tersebut yang akan digunakan untuk melakukan optimalisasi 
Management Bandwith pada suatu jaringan yang akan dilakukan untuk melakukan Limitasi Bandwith secara manual yang akan diatur pada file konfigurasi dari $H T B$ tersebut. Tools HTB digunakan untuk melakukan optimalisasi management bandwith terhadap suatu jaringan yang diterapkan pada server sehingga dapat melakukan management koneksi untuk setiap client ke jaringan server HTB.Adapun perintah untuk mengunduh file HTB sebagai berikut:

rooteubuntu: \#wgethttps://dl.dropbo x.com/s/tswxjararkluym3/HTB-tools$\underline{0.3 .0 a-i 486-1 . \operatorname{tg} z}$

Setelah Tools HTB selesai diunduh,proses selanjutnya melakukan extrack dan installasi. Installasi tools dilakukan dengan memindahkan folder $h t b$ di /sbin ke /sbin yang ada di server dengan mengetikan perintah:

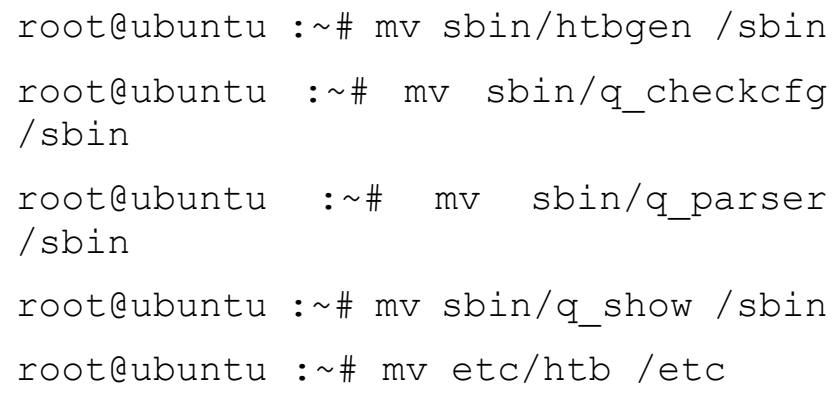

Proses selanjutnya melakukan perubahan nama file yang berada di /etc/htb dengan menghilangkan kata new pada file "eth0-qos.cfg.new" dan "eth1qos.cfg.new", dengan melakukan perintah seagai berikut:

root@ubuntu : \# mv /etc/htb/ eth0-qos.cfg.new /etc/htb/ eth0-qos.cfg

root@ubuntu : \# mv /etc/htb/ eth1-qos.cfg.new /etc/htb/ eth1-qos.cfg

Pada proses selanjutnya pindahkan file /etc/rc.d/rc.htb.new ke /etc/init.d/ dan ubah nama filenya menjadi rc.htb dengan perintah:

root@ubuntu : \#mv etc/rc.d/rc.htb.new /etc/init.d/rc.htb

Kemudian melakukan pengatuan izin akses dari file rc.htb pada folder "/etc/init.d" dengan melakukan perubahan permission sehingga dapat dieksekusi dengan menggunakan perintah:

rooteubuntu : \# chmod 775
Setelah proses diatas, selanjutnya melakukan konfigurasi terhadap file "eth1-qos.cfg" sesuai topology HTB yang akan diterapkan, jika interfaces yang berhubungan langsung dengan client adalah ethl maka yang akan dilakukan konfigurasi adalah file "eth1-qos.cfg". Adapun perintahnya sebagai berikut:

root@ubuntu : \# nano/etc/htb/eth1qos.cfg

\section{HASIL DAN PEMBAHASAN}

Berdasarkan hasil uji coba yang telah dilakukan maka dapat diperoleh hasil analisa sebagai berikut:

a. Sebelum $H T B$ diterapkan kedalam server, maka client akan melalui server terlebih dahulu sebelum melakukan koneksi internet, karena server tersebut menjadi gateway dari client.

b. Pada saat sebelum diterapkan $H T B$, client yang melakukan koneksi internet mendapatkan bandwith yang diberikan oleh Internet Service Provider tanpa dilakukan limitasi pada server.

c. Apabila Internet Service Provider memiliki bandwith lebih dari 5Mbps, maka server HTB hanya akan mengambil bandwith sebesar $5 \mathrm{Mbps}$.

d. Setelah HTB diterapkan, pada server sudah dilakukan konfigurasi untuk setiap client, konfigurasi tersebut meliputi bandwith, limit, dan upload yang dimana pada client 1 dan 2 dilakukan limitasi sebesar $2 \mathrm{Mbps}$ dan pada client 3 dilakukan limitasi bandwith sebesar 1Mbps.

e. Pada saat setelah penerapan $H T B$, pada client yang akan melakukan koneksi ke internet terlebih dahulu akan melewati server dan akan dilakukan pengecekan oleh konfigurasi $H T B$ yang terdapat pada file "/etc/htb/eth1-qos.cfg" dimana pada file konfigurasi tersebut terdapat beberapa pengaturan untuk melakukan management bandwith terhadap setiap client.

f. Pada ujicoba yang sudah dilakukan dengan pengujian menggunakan parameter yang berbeda dapat disimpulkan bahwa ujicoba yang dilakukan memiliki hasil yang sama pada pengaturan limit maupun upload.

Pembahasan selanjutnya adalah membahas hasil dari uji coba dengan menggunakan speedtest pada setiap client.Tanpa mengaktifkan HTB pada server,maka setiap client yang melakukan pengaksesan ke internet mendapatkan bandwith sepenuhnya dari internet service provider dan tidak ada pengaturan limitasi yang dilakukan pada server.Pada uji coba speesdtest ini client dapat mengetahui bandwith yang diberikan. 
Pembahasan selanjutnya adalah membahas hasil dari uji coba dengan menggunakan internet download manager pada setiap client.Tanpa mengaktifkan $H T B$ pada server, maka setiap client yang melakukan download file dari internet mendapatkan bandwith sepenuhnya dari internet service provider untuk melakukan download file, sehingga tidak ada pengaturan limitasi yang dilakukan pada server. Pada uji coba internet download manager ini client dapat mengetahui besar kecepatan bandwith yang digunakan pada saat download file.

Pembahsan selanjutnya adalah membahas hasil dari ujicoba dengan melakukan streaming youtube pada setiap client tanpa mengaktifkan HTB pada server, maka setiap client yang melakukan streaming youtube mendapatkan bandwith sepenuhnya dari internet service provider pada saat mengakses video pada youtube, sehingga tidak ada pengaturan limitasi yang dilakukan pada server.Pada uji coba streaming youtube ini client dapat mengetahui besar kecepatan bandwith yang digunakan pada saat mengakses video.

Pembahasan selanjutnya adalah membahas hasil dari uji coba dengan menggunakan speedtest pada setiap client.Setelah diterapkan HTB pada server, maka setiap client yang melakukan pengaksesan ke internet mendapatkan bandwith sesuai dari limitasi bandwith yang sudah diterapkan pada file konfigurasi $H T B$, yang dimana client 1 dan 2 diberikan bandwith sebesar $2 \mathrm{Mbps}$ dan pada client 3 diberikan $1 \mathrm{Mbps}$. Setelah diterapkan HTB pada uji coba speedtest ini, client dapat mengetahui bandwith yang diberikan oleh server HTB.

Pembahasan selanjutnya adalah membahas hasil dari uji coba dengan menggunakan internet download manager pada setiap client. Setelah diterapkan HTB pada server, maka setiap client yang melakukan download file dari internet mendapatkan bandwith sesuai dari limitasi bandwith yang sudah diterapkan pada file konfigurasi $H T B$, yang dimana client 1 dan 2 diberikan bandwith sebesar 2Mbps untuk perhitungan Kilo Byte maka $2 \mathrm{Mbps}=2048 \mathrm{KBps}$, setelah itu 2048 dibagi dengan 8 bit yang dimana hasilnya sebesar $256 \mathrm{KBps}$, dan pada client 3 diberikan $1 \mathrm{Mbps}$ untuk perhitungan Kilo Byte maka $1 \mathrm{Mbps}=1024 \mathrm{KBps}$, setelah itu 1024 dibagi dengan 8 bit yang dimana hasilnya sebesar $128 \mathrm{KBps}$. Setelah diterapkan HTB pada uji coba internet download manager ini, client dapat mengetahui besar kecepatan bandwith yang digunakan pada saat download file setelah dilakukan limitasi pada server HTB.

Pembahasan selanjutnya adalah membahas hasil dari uji coba dengan melakukan streaming youtube pada setiap client pada setiap client.Setelah diterapkan $H T B$ pada server, maka setiap client yang melakukan pengaksesan ke internet mendapatkan bandwith sesuai dari limitasi bandwith yang sudah diterapkan pada file konfigurasi $H T B$, yang dimana client 1 dan 2 diberikan bandwith sebesar 2Mbps dan pada client 3 diberikan 1Mbps. Setelah diterapkan $H T B$ pada uji coba streaming youtube ini, client dapat mengetahui bandwith yang diberikan oleh server HTB.

\section{Tabel 2 Tabel Perbandingan Sebelum Penerapan HTB}

\begin{tabular}{|l|l|l|l|l|l|}
\hline \multirow{2}{*}{ NO } & \multirow{4}{*}{ Client } & \multicolumn{3}{|l|}{ Rata-rata Sebelum Diaktifkan HTB } \\
\cline { 3 - 6 } & & \multicolumn{2}{|l|}{ Speedtest } & \multicolumn{1}{l|}{$\begin{array}{l}\text { IDM } \\
\text { (KB) } \\
\text { (Mbps) }\end{array}$} & $\begin{array}{l}\text { Youtube } \\
\text { (Mbps) } \\
\text { (Mbps) }\end{array}$ \\
\cline { 3 - 6 } 1 & $\begin{array}{l}\text { Client } \\
1\end{array}$ & 11.3 & 10.93 & $\begin{array}{l}410.92 \\
2\end{array}$ & 6.478 \\
\hline 2 & $\begin{array}{l}\text { Client } \\
2\end{array}$ & 11.37 & 10.18 & $\begin{array}{l}404.34 \\
9\end{array}$ & 7.249 \\
\hline 3 & $\begin{array}{l}\text { Client } \\
3\end{array}$ & 11.28 & 11.68 & $\begin{array}{l}404.35 \\
9\end{array}$ & 7.249 \\
\hline
\end{tabular}

Pada tabel 2 diatas terlihat nilai rata-rata dari sebelum HTB (Hierarchical Token Bucket) diaktifkan,bandwith yang digunakan pada setiap client yang mengakses internet diberikan secara penuh oleh server tanpa adanya limitasi bandwith.Tabel merupakan hasil rata-rata dari sepuluh kali percobaan yang dilakukan pada setiap client. Untuk tabel setelah diterapkan HTB dapat dilihat pada tabel 3 berikut

\section{Tabel 3 Tabel Perbandingan Sesudah Penerapan HTB}

\begin{tabular}{|c|c|c|c|c|c|}
\hline \multirow[t]{3}{*}{ NO } & \multirow[t]{3}{*}{ Client } & \multicolumn{4}{|c|}{ Rata-rata Sesudah Diaktifkan HTB } \\
\hline & & \multicolumn{2}{|c|}{ Speedtest } & \multirow{2}{*}{$\begin{array}{l}\text { IDM } \\
\text { (KB) }\end{array}$} & \multirow{2}{*}{$\begin{array}{l}\text { Youtube } \\
\text { (Mbps) }\end{array}$} \\
\hline & & $\begin{array}{l}\text { Unduh } \\
\text { (Mbps) }\end{array}$ & $\begin{array}{l}\text { Unggah } \\
\text { (Mbps) }\end{array}$ & & \\
\hline 1 & Client 1 & 1.34 & 2.00 & $\begin{array}{l}134.9 \\
41\end{array}$ & 0.979 \\
\hline 2 & Client 2 & 1.16 & 2.0 & $\begin{array}{l}150.0 \\
98\end{array}$ & 1.208 \\
\hline 3 & Client 3 & 0.8 & 0.9 & $\begin{array}{l}150.0 \\
98\end{array}$ & 0.8908 \\
\hline
\end{tabular}

Terlihat pada tabel 3 diatas merupakan tabel nilai rata-rata dari sesudah HTB (Hierarchical Token 
Bucket) diaktifkan, bandwith yang digunakan pada setiap client mendapatkan bandwith yang sudah ditentukan oleh server HTB.Tabel diatas merupakan hasil rata-rata dari sepuluh kali percobaan yang dilakukan pada setiap client untuk mengetahui besar maksimal bandwidth yang diberikan oleh server HTB.

\section{KESIMPULAN}

Berdasarkan hasil uji coba yang dilakukan dapat disimpulkan, bahwa dari penelitian terkait Analisa Penerapan Hierarchical Token Bucket Untuk Optimalisasi Management Bantdwith Pada Ubuntu Server ini, server HTB mampu menerapkan management bandwith pada suatu jaringan dan berhasil melakukan optimalisasi management bandwith pada setiap client

Pada tahap ujicoba setiap client melakukan ujicoba denan menggunakan speedtest, IDM dan streaming youtube yang dimana ketiga ujicoba tersebut digunakan untuk mengetahui bandwith yang diberikan oleh server sebelum diterapkan maupun setelah diterapkan $H T B$ dimana pada client 1 mendapatkan bandwith 2Mbps yang sebelum diaktifkan HTB rata-rata yang didapatkan pada speedtest untuk unduh $11.3 \mathrm{Mbps}$ dan unggah $10.93 \mathrm{Mbps}$, internet download manager $410.922 \mathrm{Mbps}$ dan youtube $6.478 \mathrm{Mbps}$. Sedangkan setelah diaktifkan HTB rata-rata yang didapatkan pada speedtest untuk unduh 1.34Mbps dan unggah $2.00 \mathrm{Mbps}$, internet download manager 134.941Mbps dan youtube $979 \mathrm{Mbps}$. Pada client 2 mendapatkan bandwith $2 \mathrm{Mbps}$ yang sebelum diaktifkan HTB ratarata yang didapatkan pada speedtest untuk unduh $11.37 \mathrm{Mbps}$ dan unggah $10.18 \mathrm{Mbps}$, internet download manager 404.349Mbps dan youtube 7.249Mbps. Sedangkan setelah diaktifkan HTB ratarata yang didapatkan pada speedtest untuk unduh $1.16 \mathrm{Mbps}$ dan unggah $2.00 \mathrm{Mbps}$, internet download manager $150.098 \mathrm{Mbps}$ dan youtube $1.208 \mathrm{Mbps}$. Pada client 3 mendapatkan bandwith 1Mbps yang sebelum diaktifkan HTB rata-rata yang didapatkan pada speedtest untuk unduh $11.28 \mathrm{Mbps}$ dan unggah $11.68 \mathrm{Mbps}$, internet download manager 404.359Mbps dan youtube 7.249Mbps. Sedangkan setelah diaktifkan HTB rata-rata yang didapatkan pada speedtest untuk unduh $0.8 \mathrm{Mbps}$ dan unggah $0.9 \mathrm{Mbps}$, internet download manager $150.098 \mathrm{Mbps}$ dan youtube $890.8 \mathrm{Mbps}$.

Setiap client akan mendapat bandwith sepenuhnya dari internet service provider apabila belum diterapkan Hierarchical Token Bucket pada server, sedangkan setiap client akan mendapatkan limitasi bandwith apabila sudah diterapkan Hierarchical Token Bucket pada server.

Pada ujicoba yang sudah dilakukan dengan pengujian menggunakan parameter yang berbeda dapat disimpulkan bahwa ujicoba yang dilakukan memiliki hasil yang sama pada pengaturan limit maupun upload. Dampak dari penyesuaian parameter ini seperti limit berpengaruh pada maksimum bandwith yang dapat diperoleh setiap client dan pada priority berpengaruh pada bandwith yang tersisa, maka sisa bandwith tersebut dialokasikan kepada client yang menjadi prioritas utama yang dimana prioritas dengan angka yang lebih kecil menjadi prioritas pertama.

\section{REFERENSI}

[1] L. Lukman, A. M. Saputro, A. S. Wicaksono, F. H. T. Hartomo, and M. N. Jatun, "Manajemen Bandwidth Menggunakan Metode Hierarchical Token Bucket (HTB) di Farid.net," Creative Information Technology Journal, vol. 5, no. 3, p. 209, 2019

[2] E. Manalu and D. Arisandi, "Analisa Management Bandwidth Dengan Metode Antrian Hirarchical Token Bucket," PROSIDING 2th Celscitech-UMRI 2017, vol. 2, no. 1, pp. 10-17, 2017.

[3] D. Kurnia, "Analisis QoS pada Pembagian Bandwidth dengan Metode Layer 7 Protocol, PCQ, HTB dan Hotspot di SMK Swasta AlWashliyah Pasar Senen," CESS (Journal of Computer Engineering System and Science), vol. 2, no. 2, pp. 102-111, 2017.

[4] A. M. Lukman and Y. Bachtia, "Analisis sistem keamanan jaringan dengan," Computer Engineering, System And Science, vol. 1, no. 1, pp. 9-14, 2016.

[5] M. Iqbal, P. Studi, and T. Komputer, "Perancangan Sistem Optimalisasi Manajemen Bandwidth dengan HTTB (Hierarchical Token Bucket)," Jaringan Sistem Informasi Robotik, vol. 1, no. 01, pp. 25-29, 2017.

[6] R. Tulloh, R. M. Negara, and A. N. Hidayat, "Simulasi Virtual Local Area Network (VLAN) Berbasis Software Defined Network (SDN) Menggunakan POX Controller," JURNAL INFOTEL - Informatika

Telekomunikasi Elektronika, vol. 7, no. 2, p. 129, 2015

[7] Lisnawita, "Manajemen Bandwidth Menggunakan Metode Hierarchical Token Bucket (HTB)," Jurnal Teknologi \& Komunikasi Digital Zone, 2016. 
[8] R. F. Sri Supatmi, Taufiq Nuzwir Nizar, "Perangkat Pendukung Forensik Lalu Lintas Jaringan," Jurnal Teknik Komputer Unikom Komputika, vol. 3, no. 2, pp. 32-33, 2016.

[9] F. M. Hanif, "Meningkatkan Hasil Belajar Jaringan Dasar Model Pembelajaran Berbasis Proyek (Project Based Learning) Siswa Kelas X TKJ 1 SMKN 1 Bangkinang," Jurnal Pendidikan Tambusai, 2018

[10] A. Rahmatulloh and F. MSN, "Implementasi Load Balancing Web Server menggunakan Haproxy dan Sinkronisasi File pada Sistem Informasi Akademik Universitas Siliwangi," Jurnal Nasional Teknologi dan Sistem Informasi, vol. 3, no. 2, pp. 241-248, 2017,

[11] Andrewa and S. Hendi, "Pengolahan Stok Barang Toko Dual," vol. VIII, no. 02, pp. 22-28, 2019.

[12] E. Sularno, "Analisa Dan Implementasi Iptables Dengan Debian Server Sebagai Filtering Firewall Web," vol. 3, no. 1, pp. 106-121, 2016.

[13] A. M. Syafar, "Kendali Perangkat Listrik Dan Monitoring Daya Pada MCB Berbasis TCP/IP,” Jurnal Instek, vol. 1, no. 1, 2016. 